\title{
Molecular evidence of mixed P. vivax and $P$. falciparum infections in northern Islamic Republic of Iran
}

S. Zakeri, ${ }^{1}$ S. Mamaghani, ${ }^{1}$ A.A. Mehrizi, ${ }^{1}$ Z. Shahsavari, ${ }^{1}$ A. Raeisi, ${ }^{3}$ S. Arshi ${ }^{4}$ and N. Dinparast-Djadid"

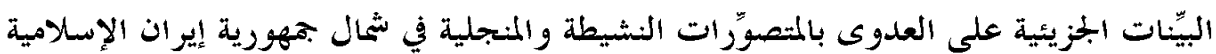

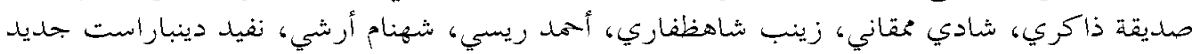

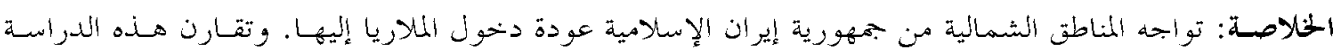

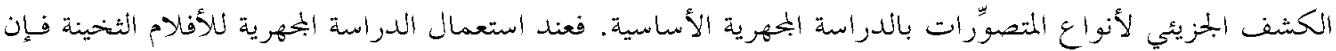

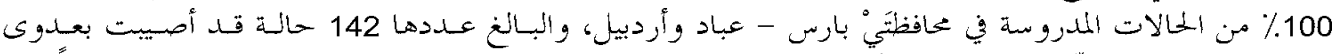

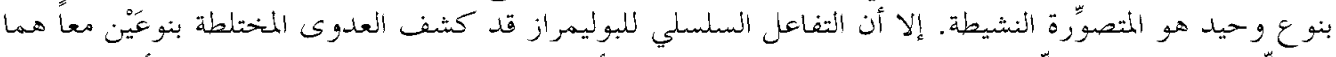

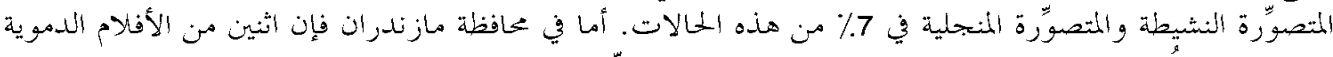

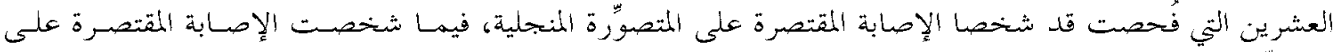

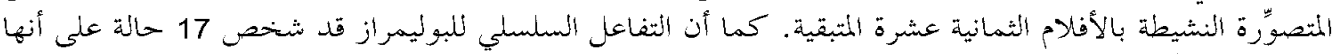

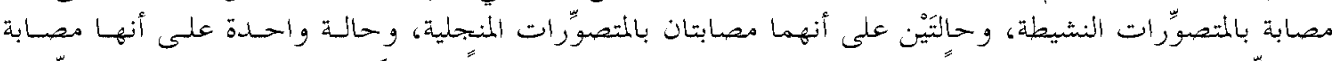

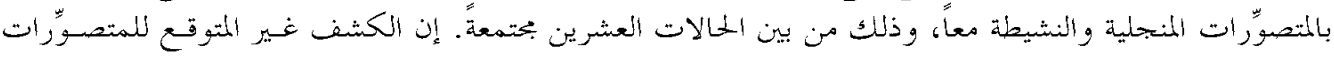

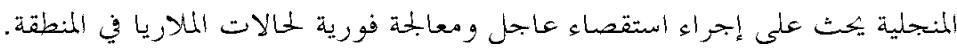

ABSTRACT This study compared basic microscopy with molecular detection of Plasmodium species. According to thick-film microscopy, $100 \%$ of 142 malaria cases in Pars-Abad, Ardebil province, were infected with a single species, $P$. vivax. However, nested polymerase chain reaction (PCR) detected mixed species infections of both $P$. vivax and $P$. falciparum in $7.0 \%$. In Mazanderan province, $2 / 20$ blood films were diagnosed with only P. falciparum and 18/20 with only P. vivax. However, nested PCR detected 17/20, $2 / 20$ and 1/20 with $P$. vivax only, $P$. falciparum only and mixed species respectively. The unexpected presence of $P$. falciparum urges prompt investigation and immediate treatment of malaria cases in this region.

Preuve moléculaire d'infection mixte par Plasmodium vivax et P. falciparum dans le nord de la
République islamique d'Iran
RESUME Cette étude a comparé la microscopie de base avec la détection moléculaire des micro-
organismes des espèces de Plasmodium. L'examen de goutte épaisse du sang a montré que $100 \%$ des 142
cas de paludisme à Pars-Abad (province d'Ardebil) étaient infectés par une seule espèce, $P$. vivax. Toutefois,
la PCR (amplification en chaîne par polymérase) nichée a permis de détecter une infection mixte par $P$. vivax
et $P$. falciparum dans $7,0 \%$ des cas. Dans la province de Mazanderan, on a trouvé $P$. falciparum seul dans
2 frottis sanguins sur 20 et $P$. vivax seul dans 18 frottis sur 20 . Toutefois, la PCR nichée a permis de détecter
P. vivax seul dans 17 frottis sur $20, P$. falciparum seul dans 2 frottis sur 20 et les deux espèces dans 1 frottis
sur 20 . La présence inattendue de $P$. falciparum impose une investigation rapide et le traitement immédiat des
cas de paludisme dans cette région.

${ }^{1}$ Malaria Research Group, Biotechnology Department, Pasteur Institute of Iran, Tehran, Islamic Republic of Iran.

${ }^{2}$ Department of Microbiology, Faculty of Science, University of Tehran, Tehran, Islamic Republic of Iran.

${ }^{3}$ Centre for Diseases Management and Control, Tehran, Islamic Republic of Iran.

${ }^{4}$ Public Health Department, Ardebil University of Medical Science, Ardebil, Islamic Republic of Iran.

Received: 23/06/03; accepted: 29/09/03

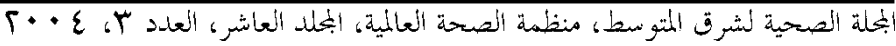




\section{Introduction}

Malaria is the world's worst health problem. Control measures are becoming less effective, and the threat of epidemic malaria is increasing in many tropical areas, mainly in relation to population movements and climatic changes. Population movements within countries or across international borders are linked to political instability and economic problems [1].

In the past, malaria was highly endemic in most parts of the Islamic Republic of Iran. In 1924, it was estimated that out of a population of 13 million, 4-5 million people had contracted malaria [2]. Since 1958, malaria infection was eradicated from most of the country; however, there is continued transmission in the south-east region and also small pockets of transmission in different parts of the country [3].

In the north and the Caspian Sea region, we are facing the re-emergence and reintroduction of malaria, especially in Ardebil and to a lesser extent in Gilan and Mazanderan provinces, through the former Soviet Union states. Here, malaria transmission was interrupted in all northern parts of Iran by 1977 , but it reappeared in 1994 following large population displacements in the border areas of Azerbaijan in 1991 [4]. From Azerbaijan, malaria was also introduced to the north-west of the Islamic Republic of Iran, which was affected by a serious epidemic of Plasmodium vivax malaria. Malaria has been seen on the Iranian side of the border, in the most receptive areas along the lowland Aras River basin, which is at an altitude of $150 \mathrm{~m}$. Along this particular valley, the villages on both sides of the border are within the flying range of Anopheles spp. The truck drivers who travel along the Aras valley to supply the Azerbaijan enclave of Nikhichevan may be carriers of the malaria parasite and facilitate the reintroduction of the disease in the north-west of the country [2].

The main malaria vector in this area is the An. maculipennis species complex (especially An. sacharovi) and the problem is resistance of this vector to dichloro-diphenyl-trichloroethane (DDT) and dieldrin. Malaria control in this area is based on case detection and treatment together with selective indoor residual spraying [5].

The diagnosis of malaria still relies on identification of the malaria parasite by light microscopy of Giemsa-stained thick and thin blood smears. This procedure is cheap and simple, but it is labour-intensive and requires personnel who are well trained in the morphological differentiation of the Plasmodium spp. [6] in order for successful diagnosis and treatment. Rapid nonmicroscopic tests for the detection of Plasmodium spp. infection, based on molecular biological techniques, have been introduced to overcome problems associated with the low sensitivity in diagnosing malaria infections with a low level of parasitaemia by microscopy.

The aim of this study was to determine the prevalence of Plasmodium spp. in the northern part of the Islamic Republic of Iran and to carry out correct species identification using polymerase chain reaction (PCR) methods for the first time in these areas. We also aimed to assess the accuracy of basic microscopy and to compare PCR-based diagnosis with microscopy results, in order to determine the frequency of mixed malaria infections and, ultimately, to improve the diagnosis and control of malaria in this area of the country.

\section{Methods}

\section{Population and study area}

The main study was conducted in the city of Pars-Abad, Ardebil province, located in a

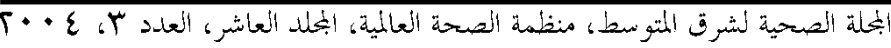


westward extension of the Mughan steppe, most of which lies within Azerbaijan. Malaria transmission is markedly seasonal, with cases peaking in June-September. According to the annual report of the Iranian Centre for Disease Management and Control (CDMC) in 2002, the annual parasite incidence (API) was reported to be 0.27 per 1000 population [unpublished data]. A total of 142 malaria patients aged from 1.5 to over 70 years attending the Malaria Diagnostic Laboratory in Pars-Abad were invited to participate in this study during June to October 2002.

A smaller study was conducted in Mazanderan province in the northern part of Iran near the Caspian Sea. Here, malaria transmission is seasonal with a peak in June-September and the API was reported to be 0.05 per 1000 population. Most cases are Afghan refugees, who are migrating to the north of the Islamic Republic of Iran. A total of 20 samples were collected from malaria patients aged 16-61 years from different parts of Mazanderan province during June-September 2002.

\section{Data collection}

On arrival of the patients at the clinic, thick and thin blood smears were made from finger-prick samples on separate slides. Before treatment, and after obtaining informed consent, $2 \mathrm{~mL}$ venous blood was collected by the clinic staff from patients with slide-confirmed Plasmodium infection. Samples were stored at $-20{ }^{\circ} \mathrm{C}$ and sent to the Malaria Research Group at the Pasteur Institute in Tehran for further analysis.

\section{Microscopy tests}

For malaria parasite detection by microscopy, thick and thin blood smears were fixed and stained with $10 \%$ Giemsa and examined under oil-immersion $(100 \times)$ for 100 fields by expert microscopists at the local malaria diagnostic laboratory in the study areas. To confirm the results, all smears were sent to the Pasteur Institute in Tehran and examined by staff at the biotechnology department of the Malaria Research Group.

Parasite species were identified using both thick and thin film preparations. The percentage of the parasitaemia was calculated from a total count of 1000 red blood cells (RBC) in a Giemsa-stained thin blood film [7]:

$$
\begin{aligned}
\% \text { parasitaemia }= & \text { total no. infected } \mathrm{RBC} \\
& \times 100 / \text { total no. } \mathrm{RBC}
\end{aligned}
$$

\section{PCR analysis}

Extraction of parasite deoxyribonucleic acid (DNA) was carried out as described by Snounou et al. [8]. Briefly, $500 \mu \mathrm{L}$ of blood samples were thawed on ice before being mixed with cold phosphate-buffered saline. The parasite DNA was extracted after the lysed erythrocytes had been treated with saponin followed by proteinase K, using a phenol:chloroform mixture. The positive control DNAs were as follows: $P$. falciparum-infected blood was obtained from in vitro cultured parasites routinely maintained at the Pasteur Institute of Iran. DNA samples of $P$. vivax were obtained from patients in the southern part of Iran [7] and P. malariae was kindly provided by the Pasteur Institute of France.

DNA samples were processed by PCR to amplify species-specific sequences of the small subunit ribosomal ribonucleic acid (ssrRNA) genes of $P$. vivax, $P$. falciparum, and $P$. malariae using primers and cycling parameters as described previously [8].

Two negative controls were included in each set of amplification reactions: 1 with no DNA and 1 from genomic DNA prepared from healthy individuals with no his-

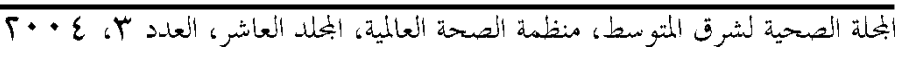


tory of malaria who were living in nonmalarious areas of the country. The amplified products were resolved by $2.5 \%$ agarose gel electrophoresis for $P$. vivax, $P$. falciparum and $P$. malariae and stained with ethidium bromide for visual detection by ultraviolet transillumination.

In order to prevent cross-contamination, different sets of pipettes and different work areas were used for template preparation, preparation of master mix for PCR, addition of template to first and second 'nests' and PCR assays; 1 uninfected blood sample was included for every 10 samples processed.

\section{Results}

Of the 142 blood samples from malaria patients in Pars-Abad, Ardebil province, 77 $(54.2 \%)$ were from females and 65 (45.8\%) males; their ages ranged from 1.5 to 70 years old. The highest proportion was in the age group 11-20 years. All cases were local inhabitants of Iranian nationality.

Using light microscopy of thick blood films by local technicians, all $142(100 \%)$
Giemsa-stained slides were identified as having only P. vivax infection. No P. falciparum and mixed infections were diagnosed (Table 1). The thin films showed that parasitaemia ranged from $0.01 \%$ to $4.70 \%$, with a mean of $0.74 \%$. The results of the PCR assays (Table 1) were as follows. Plasmodium spp. were detected in all $(100 \%)$ collected blood samples: 132 (93.0\%) infections were due to $P$. vivax only and $10(7.0 \%)$ due to mixed $P$. vivax and $P$. falciparum infections. No P. falciparum alone or $P$. malariae infections were detected.

Of the 20 malaria patients in Mazanderan province, $2(10 \%)$ were females and 18 $(90 \%)$ males. Twelve (12) patients out of 20 were immigrants from Afghanistan, who came to the province for work.

In the microscopy analysis of thick blood films, 18 samples out of 20 were diagnosed as only $P$. vivax infection; however, 2 were $P$. falciparum alone. No mixed infection was diagnosed (Table 2). The results of the PCR assays showed 17 $(85.0 \%)$ were due to $P$. vivax infection alone and $2(10.0 \%)$ to $P$. falciparum alone (Table 2). One sample showed both $P$.

\begin{tabular}{|c|c|c|c|c|}
\hline \multicolumn{5}{|c|}{$\begin{array}{l}\text { Table } 1 \text { Comparison of nested polymerase chain reaction } \\
\text { (PCR) assay with Giemsa staining for detection of } \\
\text { Plasmodium spp. infection in malaria patients from Pars- } \\
\text { Abad, Ardebil province }\end{array}$} \\
\hline \multirow[t]{2}{*}{ PCR diagnosis } & \multicolumn{4}{|c|}{ Microscopy diagnosis } \\
\hline & $\begin{array}{c}\text { P. vivax } \\
\text { No. }\end{array}$ & $\begin{array}{c}P . \\
\text { falciparum } \\
\text { No. }\end{array}$ & $\begin{array}{c}\text { P. vivax + } \\
\text { falciparum } \\
\text { No. }\end{array}$ & $\begin{array}{c}\text { Total } \\
\text { No. }\end{array}$ \\
\hline P. vivax & 132 & 0 & 0 & 132 \\
\hline P. falciparum & 0 & 0 & 0 & 0 \\
\hline $\begin{array}{l}\text { P. vivax }+ \\
\quad \text { falciparum }\end{array}$ & 10 & 0 & 0 & 10 \\
\hline Total & 142 & 0 & 0 & 142 \\
\hline
\end{tabular}

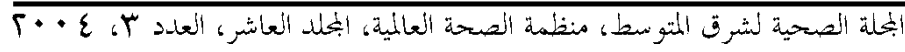




\begin{tabular}{lcccc}
\hline $\begin{array}{l}\text { Table } 2 \text { Comparison of nested polymerase chain reaction } \\
\text { (PCR) assay with Giemsa staining for detection of } \\
\text { Plasmodium spp. infection in malaria patients from } \\
\text { Mazanderan province }\end{array}$ \\
\hline $\begin{array}{l}\text { PCR diagnosis } \\
\text { P. vivax }\end{array}$ & $\begin{array}{c}\text { Microscopy diagnosis } \\
\text { P. } \\
\text { falciparum } \\
\text { No. vivax + } \\
\text { falciparum }\end{array}$ & Total \\
No. & No. & No. & No. \\
\hline $\begin{array}{l}\text { P. vivax } \\
\text { P.falciparum }\end{array}$ & 17 & 0 & 0 & 17 \\
$\begin{array}{l}\text { P. vivax+ } \\
\text { falciparum }\end{array}$ & 0 & 2 & 0 & 2 \\
Total & 1 & 0 & 0 & 1 \\
\hline & 18 & 2 & 0 & 20 \\
\hline
\end{tabular}

vivax and $P$. falciparum mixed infections, but this was not detected by routine microscopy.

\section{Discussion}

In the 1990s, central Asia experienced considerable problems in preventing and controlling malaria. The wars and political instability in Afghanistan and Iraq and the difficult economic and social conditions among the former republics of the Soviet Union have resulted in human migration, and consequently a reduction in the quality of health services. The shortage of essential equipment and supplies for malaria prevention and control has also weakened malaria prevention activities. Lack of knowledge and experience in malaria prevention and control among health service staff has been another obstacle in the planning and effective implementation of these measures [4].

At present, there are 3 areas in central Asia that cause concern for countries of the Eastern Mediterranean Region. Afghanistan is a source of importation of malaria to all its neighbours. In particular, the oriental type of $P$. falciparum is widespread in some areas of the country. In areas on the borders between the Islamic Republic of Iran, Azerbaijan, and to some extent Armenia, malaria transmission was interrupted by 1977, but reappeared in 1994 following large displacements of the population in the border areas of Azerbaijan in 1991. The malariogenic potential on the Iranian side is quite high along the Aras River at altitudes below $150 \mathrm{~m}$. North Iraq also has a problem of $P$. vivax malaria that sometimes leads to epidemics.

In the Islamic Republic of Iran, malaria is also affected by those 3 countries and the constantly increasing population movements have led to importation of malaria cases from neighbouring countries. In 1958 , we started the national malaria eradication programme, which changed to malaria control in 1987 due to technical problems and administrative difficulties [3]. The main anti-malaria measures in the country are early detection and treatment of cases, and indoor residual spraying in foci of transmission. 
The Islamic Republic of Iran has 3 epidemiological zones of malaria [2]. Zone 1 in the northern part of the Zagros mountain chain consists of 16 provinces inhabited by 43 million people. In 2002, there were 3060 cases in this region. The annual parasite incidence (API) was approximately 0.07 per 1000 people and 2882 (94\%) of total cases were $P$. vivax malaria. Most of the provinces in this zone were clear of malaria, but after 1994, some new foci appeared in this region, particularly in the border area between the Islamic Republic of Iran and the Republic of Azerbaijan and Armenia. In Zone 2, are regions to the south of the Zagros range with a population of approximately 15 million. The API in 2002 was reported to be 0.11 per 1000 in total cases of 1726 . More than $88 \%$ of the cases in this zone are imported, which led to the establishment of 2 new foci in Bushehr and Fars provinces during the year 2002. In this zone, the dominant parasite $(89 \%$ of total cases) is also $P$. vivax. Zone 3 consists of 3 provinces, Hormozgan, Kerman and Sistan va Baluchistan, inhabited by approximately 3 million people. The API was 2 per 1000 in 2002. The total malaria cases in the whole country in 2002 was 15558 with an API of 0.24 per 1000 population and about $70 \%$ (10 772) of cases were from zone 3. Also $85 \%$ of total reported P. falciparum cases were from zone 3 .

$P$. falciparum infection has been eradicated from most areas of the Islamic Republic of Iran and the underlying reason for the continued transmission of this species in the south-east is probably due to the fact that $P$. falciparum belongs to the oriental ecological system. However, in the rest of the country, small pockets of transmission still exist [2]. The official records of malaria cases in Ardebil (north-west) and Mazanderan (north) provinces in 2002 showed 339 and 135 cases, respectively. All cases were diagnosed as only P. vivax in Ardebil and 130 were diagnosed as only $P$. vivax, with 5 P. falciparum/mixed infection in Mazanderan provinces. No mixed infection was diagnosed by light microscopy methods in Ardebil.

In Pars-Abad, Ardebil, our study using nested PCR analysis found 7\% of mixed $P$. vivax/P. falciparum infections among cases microscopically diagnosed as $P$. vivax only. Also $60 \%$ of Mazanderan's cases were Afghan immigrants who came from Afghanistan or the south-eastern part of the Islamic Republic of Iran. There is a risk, therefore, of introducing new isolates, including drug resistant parasites from south-east to north and this may stimulate outbreaks in this part of the country. Untreated patients with missed diagnosis of $P$. vivax and $P$. falciparum infections could be carriers of the malaria parasites within and between provinces and spread malaria to areas where malaria was interrupted before. Potentially, because of the presence of about 21 Anopheles species (5-6 in most provinces) in different zoogeographical areas, the Islamic Republic of Iran has a high risk for malaria transmission. Entomological and parasitological surveillance must be considered since the risk of returning malaria from in and/or outside neighbouring countries is very high.

Our results showed an unexpected presence of $P$. falciparum in the Palaearctic zoogeographic region, among the population in Ardebil province. Cases of $P$. falciparum infection outside of south-east Iran (Oriental zoogeographic region) should be given emergency status, prompt investigation and immediate treatment of malaria cases.

The presence of Afghan refugees in Mazanderan province should be considered in surveillance and monitoring of the malaria parasite, as they may harbour resistance

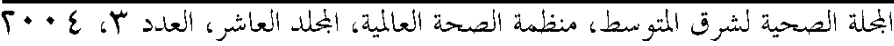


to $P$. falciparum parasites, which may originate from Afghanistan or southeastern parts of the Islamic Republic of Iran and spread to the northern part of the country. A resurgence of transmission in areas where malaria was interrupted may then cause epidemics during which the entire population is vulnerable to malaria.

In this study, in addition to aiding diagnosis, we used a sensitive parasite detection system to understand the dynamics of parasite infection in the northern part of the Islamic Republic of Iran. The outcome of this study could also help to prevent spread of this disease, coordination of anti-disease activities and standardization of control methods between the 3 countries in border areas: the Islamic Republic of Iran, Azerbaijan and Armenia.

\section{Acknowledgements}

We thank the Malaria Division, CDMC, Islamic Republic of Iran, for their cooperation. We are grateful for the hospitality and generous collaboration of the malaria patients and field teams and microscopists in Pars-Abad, especially Mr D. Emdadi and Mr M. Kazemi, and Mr Yazdanian in Mazanderan province.

We also thank Georges Snounou at the Pasteur Institute in France for generous assistance with the nested PCR primers and detection protocols. We are also grateful to all members of the Department of Biotechnology, Pasteur Institute, especially Dr S. Zeinali. This work was supported partially by the Pasteur Institute of Iran.

\section{References}

1. Roll back malaria. Prevention and control of malaria epidemics. 3rd meeting of the Technical Support Network. Geneva, World Health Organization, 2002 (WHO/CDS/RBM/2002.40). http://www. doh.gov.za/issues/malaria/ red_reference/epidemics/epi3.pdf (accessed 29/08/04).

2. Sadrizadeh B. Malaria in the world, in the eastern Mediterranean region and in Iran: review article. Archives of Iranian medicine, 1999, 2(4).

3. Manouchehri AV, Zaim M, Emadi AM. A review of malaria in Iran, 1975-1990. Journal of the American Mosquito Control Association, 1992, 8:381-5.

4. Prevention of cross-border transmission of malaria. Report on a WHO coordination meeting Baku, Azerbaijan 24-25 August 1999. Copenhagen Denmark, WHO Regional Office for Europe (EUR/ ICP/ CMDS 0803 01). http:// www.euro.who.int/document/ E67223.pdf (accessed 29/08/04).
5. Zaim M. Malaria controls in Iran: present and future. Journal of the American Mosquito Control Association, 1987, 3(3): 392-6.

6. Tham JM et al. Detection and species determination of malaria parasites by PCR: comparison with microscopy and with ParaSight-F and ICT malaria Pf tests in a clinical environment. Journal of clinical microbiology, 1999, 37(5):126973.

7. Zakeri $\mathrm{S}$ et al. Detection of malaria parasites by nested PCR in south-eastern, Iran: evidence of highly mixed infections in Chahbahar district. Malaria journal, 2002, 1:2.

8. Snounou $\mathrm{G}$ et al. High sensitivity of detection of human malaria parasites by the use of nested polymerase chain reaction. Molecular and biochemical parasitology, 1993, 61:315-20.

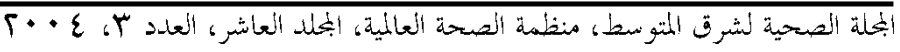

